\title{
LONG RANGE RECEPTION WITH COMBINED CRYSTAL DETECTOR AND AUDION AMPLIFIER*
}

\author{
$\mathrm{BY}$ \\ HaRaden Pratt
}

In the early part of the present year, an antenna was erected at the University of California to receive the time signals from Arlington, which station was then engaged in the Paris-Arlington longitude difference tests. The writer was thus enabled to conduct some interesting experiments in long distance reception during February, March, and April.

On the western coast of the United States, the radio conditions appear to be unusually favorable during the winter months. This is particularly the case in the San Francisco Bay region, where the almost complete absence of thunder storms and, in fact, atmospherics of any strength during the time mentioned makes the reception of signals from very distant stations nearly continuously possible.

The first antenna used in these experiments consisted of a wire 750 feet (230 meters) long supported at one end on a 300 foot (92-meter) steel tower, and by an 80-foot (24.5-meter) stack at the end nearer the receiving apparatus. The results obtained were so encouraging that two extra wires, spaced about 3 feet $(92 \mathrm{~cm}$.) apart were subsequently added. The strength of the signals was practically doubled by their presence. The fundamental or natural wave length of the antenna system was about 1,170 meters.

The receiving apparatus differed from the usual type only in that a galena-audion amplifying combination was used. The latter arrangement was based on the following principles.

It is at present understood that the audion detector possesses two distinct and separable properties in connection with currents of radio frequency. Firstly: because of the unilateral conductivity of the region around the heated filament, oscillating currents in passing across any portion of this region suffer a

* Delivered before The Institute of Radio Engineers, New York, December 2, 1914 . 
partial rectification. Thus one current impulse per wave train is produced, and an ordinary polarized telephone receiver can be affected by the transformed energy. Secondly: in the audion, the potential gradient across the rarefied gas, from the filament outward, is not linear. And the total potential difference across this space is brought to a critical value such that any further increase in it will cause a large current to flow. We have thus an amplifier and rectifier combined. The amplifying quality differs considerably in different bulbs, the shape of the E-I curve being an individual characteristic of the bulb.

A very good galena crystal and an audion bulb of fair sensitiveness were available in these experiments. When the two were used in combination, the audibility of received signals was enormously increased. It is interesting to note that there are many possible combinations of these detectors, and that a large number were tried before a successful one was found.

Five changeable features exist which affect the sensitiveness of the combination. They are:

1. Polarity of the filament battery,

2. Polarity of the secondary ("B") battery,

3. Interchanging of the galena detector terminals,

4. Interchanging of the grid and plate, and

5. Interchanging of the terminals of the secondary of the receiving transformer.

Each of these features was found to affect the strength of the signals received in the telephone. There was, indeed, one good combination out of 120 possibilities. The proper arrangement under conditions 1,2 , and 4 could be quickly found, however, because of the extreme effects produced when the adjustment was incorrect. The reason for including condition 5 is that the capacity between the primary and the secondary of the receiving transformer and the capacity of the audion apparatus to ground were different for the two modes of connection.

The results obtained with this combination of galena and audion were very satisfactory, previously inaudible signals becoming perfectly readable. To determine the amount of the amplification numerically, and to show the constancy of adjustment, a number of measurement of the audibility of signals were taken. The galena detector was used as the basis of comparison in these measurements, not only because of its steadiness and ease of adjustment, but also because it is representative of the best ordinarily used rectifying detectors. The shunted 
telephone method of measuring audibility was employed. Constancy of the galena detector adjustment was controlled from day to day by noting the audibility of a buzzer signal kept constant in intensity thruout the experiments.

The values tabulated below give the mean of more than 200 independent values taken over a period of 30 days. The stations ranged in distance from close at hand to over 5,000 miles $(8,000$ $\mathrm{km}$.) away. They lay in all directions from the receiving station; their wave lengths were between 600 and 3,200 meters, and their spark frequencies between 100 and 1,000 per second.

In the columns headed " 1 ," are given the audibility using galena alone, in columns " 2 " the audibility using galena and the audion. Columns " 3 " give the ratio of these audibilities, that is, the amplification ratio.

\begin{tabular}{|c|c|c|c|c|c|}
\hline $\begin{array}{c}1 \\
\text { Audibility } \\
\text { with } \\
\text { Galena }\end{array}$ & $\begin{array}{c}2 \\
\text { Audibility } \\
\text { with } \\
\text { Combination }\end{array}$ & Ratio & $\begin{array}{c}1 \\
\text { Audibility } \\
\text { with } \\
\text { Galena }\end{array}$ & $\begin{array}{l}2 \\
\text { Audibility } \\
\text { with } \\
\text { Combination }\end{array}$ & Ratio \\
\hline 507.0 & 3541.0 & 7.0 & 5.0 & 60.0 & 12.0 \\
\hline 3.5 & 36.4 & 10.3 & 18.3 & 273.0 & 15.1 \\
\hline 4.5 & 51.6 & 11.4 & 26.2 & 254.0 & 9.7 \\
\hline 2.7 & 30.5 & 11.3 & 6.0 & 51.8 & 8.6 \\
\hline 1.5 & 18.7 & 12.5 & 90.5 & 895.0 & 9.9 \\
\hline 9.8 & 118.6 & 12.0 & 13.0 & 102.0 & 7.8 \\
\hline 4.5 & 60.0 & 13.2 & 26.0 & 355.0 & 13.6 \\
\hline 8.0 & 72.0 & 9.0 & 13.0 & 119.0 & 9.1 \\
\hline 28.0 & 253.0 & 9.0 & 51.0 & 505.0 & 9.9 \\
\hline
\end{tabular}

Average Amplification $=10.6$

The average value of the amplification is, therefore, about 10 . In order to note the effect of changing the " $\mathrm{B}$ " battery potential across the audion when using the adjusting telephone shunt, another pair of telephones was kept in series with the measuring pair and shunt. By listening in this extra pair of receivers, it was found that adjusting the shunt for audibility measurements did not disturb the signals. No single set of observations on one signal was averaged for more than one half hour's readings.

In carrying on these experiments it was noticed that audion bulbs which served excellently as detectors when used alone were not necessarily of value when used in combination with the galena as an amplifier. To determine the proper characteristics of an audion bulb for use in connection with the galena, some further experiments were tried. 
It was noted first that, with certain values of the " $B$ " battery potential of the audion, the clicks in the telephone while adjusting the galena crystal became weak, and the ease of manipulation was much increased. On the other hand, at other values of the "B" battery voltage, the clicks were loud and the crystal adjustment could be made only with considerable trouble.

A microvoltmeter was placed across the galena crystal, and it was found that for a certain value of the " $\mathrm{B}$ " battery voltage of the audion, no potential difference existed across the crystal. It was with this adjustment that the crystal could be adjusted and used most easily. Using one of the crystals, the relation between the " $\mathrm{B}$ " battery voltage and the potential across the crystal was determined. A curve showing this relation is shown in Figure 2. (Figure 1 shows the normal arrangement of the circuits.) It is interesting to note that for zero potential across

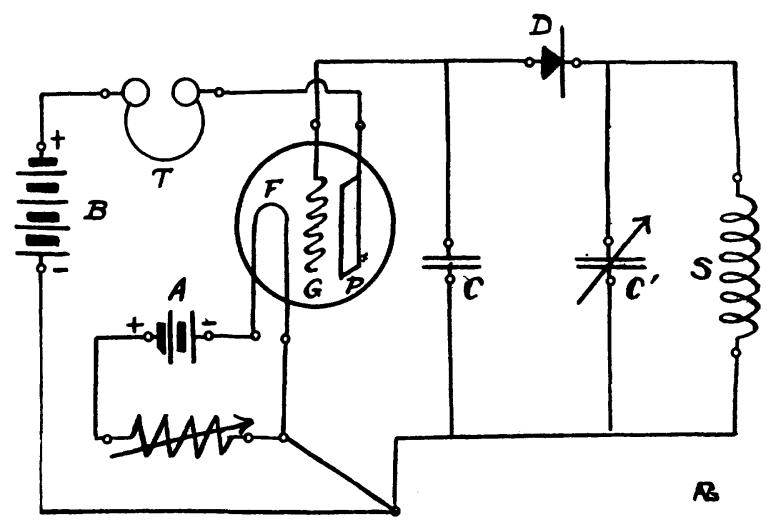

Figure 1

the crystal, the " $\mathrm{B}$ " battery voltage for the particular audion used was nearly the critical value for that particular bulb. The point of zero potential across the crystal could be brought to coincidence with the critical " $\mathrm{B}$ " battery value of the voltage by slightly varying the filament (or " $\mathrm{A}$ " battery) voltage.

With poor audion bulbs, unsuited for use as amplifiers in conjunction with galena crystals, these conditions were not found to exist. The " $\mathrm{B}$ " battery potential could be varied, but the crystal potential never fell to a very low value. When the " $B$ " battery potential was increased, the crystal potential difference diminished, but the blue light would appear in the bulb showing that the critical potential value had been passed, and saturation 
reached. No variation in the value of filament current could alter this condition.

It appears that unless the "B" battery potential can be brought to a critical value and at the same time the crystal potential difference is zero, satisfactory operation of this device cannot be secured.

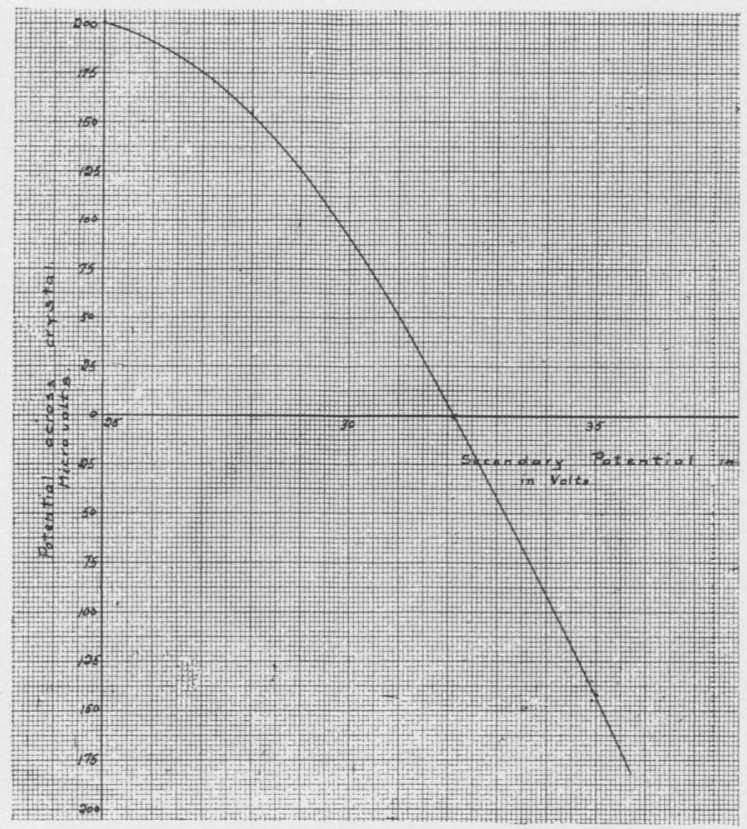

FigURE 2

During the month of February, 1914, using the amplifier described, signals were received from Sayville (Long Island, New York), Arlington (Virginia), Key West (Florida), Colon (Panama), stations in Alaska, and others including a station in eastern Siberia. One night, signals were heard from two Telefunken stations, one in the Marshall Islands, and the other on Yap Island in the Caroline group. The distances of these stations from San Francisco are respectively 5,100 miles $(8,200 \mathrm{~km}$.) and 6,100 miles $(9,800 \mathrm{~km}$.). These signals were heard every night for three months thereafter with a nearly steady audibility of 25. The strength of signals varied but slightly from night to night. Nevertheless these stations experienced great difficulty in working with each other, altho they were but 2,100 miles $(3,400 \mathrm{~km}$. $)$ apart. The more distant station of the two could 
with difficulty be heard using either the audion or galena alone, but with the combination, signals were always readable up to the month of May, when the summer atmospherics began to interfere. Local signals caused no interference as the wave length of these stations was above 3,000 meters.

SUMMARY: If an audion bulb is used as an ordinary receiver, across the "stopping" condenser in series with a galena detector, an amplification of signals of about ten times is attained. The audion bulb used, to be effective for this purpose, must have certain definite voltage-current characteristics, which are described. The circuit diagram is given. Working with an antenna of an approximate fundamental wave length of 1,200 meters, a number of observations on stations up to $8,000 \mathrm{~km}$. away were made. 